\title{
Influence of Low Total Triiodothyronine Levels on Bone Turnover Markers in Type 2 Diabetes Mellitus
}

\author{
Zelin $\mathrm{Li}^{1,2}$ \\ Xian $\mathrm{Yu}^{2}$ \\ Luping $\operatorname{Ren}^{2}$ \\ Zi Wang ${ }^{3}$ \\ Fei Wang ${ }^{1,2}$ \\ Yujiao Jia ${ }^{1,2}$
}

Shuchun Chen ${ }^{1,2,4}$

'Graduate School of Hebei Medical University, Shijiazhuang, Hebei, People's Republic of China; ${ }^{2}$ Department of Endocrinology, Hebei General Hospital, Shijiazhuang, Hebei, People's Republic of China; ${ }^{3}$ Department of Infectious Diseases, Shanghai Fourth People's Hospital, Shanghai, People's Republic of China; ${ }^{4}$ Hebei Key Laboratory of Metabolic Diseases, Shijiazhuang, Hebei, People's Republic of China
Correspondence: Shuchun Chen Department of Endocrinology, Hebei General Hospital, Shijiazhuang, Hebei, People's Republic of China

Tel +86 3II 85988406

$\mathrm{Fax}+8631185988406$

Email chenshuc20I4@I63.com
Purpose: The aim of this study was to investigate whether low total triiodothyronine (TT3) could affect bone turnover in patients with type 2 diabetes mellitus (T2DM).

Materials and Methods: This is a cross-sectional study that recruited 577 patients with T2DM, 141 patients formed the low TT3 group (TT3<1.30nmol/L) and 436 patients formed the control group $(\mathrm{TT} 3 \geq 1.30 \mathrm{nmol} / \mathrm{L})$, and the low TT3 group was further subdivided into four groups based on the TT3 level. To investigate whether TT3 level is associated with poor glycemic control, all participants were divided into high glycosylated hemoglobin (HbAlc) group and low HbA1c group using $\mathrm{HbA1c} 10.5 \%$ as the boundary.

Results: The levels of OC and PINP were significantly lower in the low TT3 group compared with the control group $(P<0.05)$. TT3 positively correlated with OC and PINP ( $\mathrm{r}=0.219, \mathrm{P}=0.009 ; \mathrm{r}=0.208, P=0.019$ ) in the low TT3 group, and this positive correlation still existed after adjusting for other factors in multilinear regression analysis. Next, we want to find a cut-off point to prevent osteoporosis, we divided the patients in the low TT3 group into four groups based on the TT3 level, the levels of OC and PINP were significantly lower in the TT3 $<1.00 \mathrm{nmol} / \mathrm{L}$ group than in the TT3 $\geq 1.00 \mathrm{nmol} / \mathrm{L}$ groups. Conclusion: In patients with T2DM, low TT3 levels are associated with impaired bone formation. What's more, bone formation was significantly impaired when TT3 was $<1.00$ $\mathrm{nmol} / \mathrm{L}$.

Keywords: bone turnover markers, low TT3 level, thyroid hormones, type 2 diabetes mellitus

\section{Introduction}

Diabetes and thyroid dysfunction are the two most common endocrine diseases in clinical practice, ${ }^{1}$ and they often co-occur. Insulin and thyroid hormones play an essential role in metabolism and interact with each other. Compared with the healthy population, patients with diabetes are more susceptible to thyroid dysfunction. A study found that the prevalence of type 2 diabetes mellitus (T2DM) with thyroid dysfunction in older adults in China was $23.9 \%$. $^{2}$ As a metabolic disease, diabetes has gradually become a public health problem of global concern, it can cause a variety of complications, including osteoporosis. Similarly, osteoporotic is common, with an estimated 120 million osteoporosis patients in China in the year $2000 .^{3}$ Thyroid dysfunction is a risk factor for osteoporosis. In fact, untreated, hyperthyroidism, subclinical hyperthyroidism and hypothyroidism are established causes for secondary osteoporosis. In the absence of primary thyroid dysfunction, 
changes in circulating thyroid hormone parameters are often observed in systemic non thyroid diseases, such as T2DM. ${ }^{4}$ Patients with T2DM are more likely to suffer from low total triiodothyronine (TT3) levels compared with healthy people, this finding is more common in people with poor glycemic control. ${ }^{5,6}$ It is not clear whether the low TT3 levels in patients without thyroid disease especially in T2DM patients. We evaluated whether low TT3 levels are associated with bone turnover markers (BTMS).

To date, no study explored whether low TT3 levels affected bone turnover in patients with T2DM. In our hospital, the low TT3 level is defined as TT3 $<1.3 \mathrm{nmol} / \mathrm{L}$. Considering the importance of thyroid hormones in the bone, the purpose of this study was to investigate: 1) The relationship between low TT3 levels and levels of bone turnover markers (BTMs) in patients with T2DM; 2) Stratified experiments were conducted in patients with low TT3 levels according to the TT3 levels to find the cutoff point; 3) Whether poor glycemic control can affect TT3 level. It provided a basis for the early intervention and prevention of the occurrence and development of osteoporosis in patients with T2DM.

\section{Materials and Methods Study Population}

This was a hospital-based cross-sectional study, which was conducted in the Department of Endocrinology, Hebei General Hospital, from December 2018 to December 2019. Patients complying with the WHO diagnostic criteria for diabetes, 1999, were included. Patients with thyroid diseases, such as hyperthyroidism, hypothyroidism, subclinical hypothyroidism and subclinical hyperthyroidism, patients with acute and chronic diabetic complications, pregnant women, patients with hepatic or renal dysfunction or malignant tumor, and patients using agents that could affect bone metabolism were excluded. This study was approved by the medical ethics committee of Hebei General Hospital, and all patients signed the informed consent form before enrollment. This study was conducted in accordance with the Declaration of Helsinki.

\section{Information and Biomarkers Collection}

All participants completed a questionnaire to collect basic information, including gender, age, duration of disease. Height, weight were measured twice by professional, and the average value was recorded. Blood samples were collected from the patients after $8 \mathrm{~h}$ of fasting. The levels of total cholesterol (TC), triglyceride (TG), high-density lipoprotein cholesterol (HDL-C), low-density lipoprotein cholesterol (LDL-C), fasting blood glucose (FBG), glycated hemoglobin (HbAlc), total triiodothyronine (TT3), total thyroid hormone (TT4), TSH, OC, $\beta$-CTX, and PNIP were measured.

\section{Statistical Analysis}

All analyses were conducted using Statistical Product and Service Solutions 25.0 (SPSS 25.0). The normality of the distribution was tested using the Kolmogorov-Smirnov test. Continuous variables are presented as median (25th, 75th interquartile range) and mean \pm standard deviation values. For categorical variables, data were expressed as numbers (percentages). The biochemical parameters between two groups were compared using the Student $t$-test or Mann-Whitney test. $\chi 2$ test was employed to compare categorical variables. The biochemical parameters in the four subgroups of the low TT3 group were compared using analysis of variance or Kruskal-Wallis $H$-test. The correlations between BTMs and TT3, TT4, TSH, and other biochemical parameters were analyzed using Pearson and Spearman correlation tests. Multiple linear regression analysis was used to study the independent correlation between TT3 and BTMs. A P value less than 0.05 was considered statistically significant.

\section{Results}

\section{Clinical Characteristics of All Participants}

A total of 577 patients with T2DM (208 female and 369 male) were included in this study. The mean age was 58.00 years, the mean BMI was $25.83 \mathrm{~kg} / \mathrm{m}^{2}$ and the mean diabetes duration were 10 years. In the cohort of all participants, the mean FBG level was $8.52 \mathrm{mmol} / \mathrm{L}$ and the mean HbAlc level was $8.90 \%$ (Table 1 ). The mean TT3 level was $1.45 \mathrm{noml} / \mathrm{L}$, and the 141 patients had low TT3 levels $($ TT3 $<1.30 \mathrm{nmol} / \mathrm{L}$ ).

\section{Comparison of Basic Parameters Between the Low TT3 Group and Control Group}

The levels of OC, PINP were significantly lower in the low TT3 group than in the control group $(\mathrm{P}<0.001, \mathrm{P}<$ 0.001 , respectively). However, the levels of bone resorption marker $\beta$-CTX showed no significant difference 
Table I Clinical Characteristics of All Participants

\begin{tabular}{|l|c|}
\hline & Subjects $(\mathbf{n}=577)$ \\
\hline Gender & Male $(369,63.95 \%)$ \\
Age & $58.00(49.00,67.00)$ \\
DM duration (years) & $10.00(3.00,15.00)$ \\
BMI $\left(\mathrm{kg} / \mathrm{m}^{2}\right)$ & $25.83(23.44,27.94)$ \\
TC $(\mathrm{mmol} / \mathrm{L})$ & $4.68(3.93,5.54)$ \\
TG $(\mathrm{mmol} / \mathrm{L})$ & $1.43(1.01,2.08)$ \\
LDL-C $(\mathrm{mmol} / \mathrm{L})$ & $2.94(2.16,3.56)$ \\
HDL-C $(\mathrm{mmol} / \mathrm{L})$ & $1.10(0.93,1.36)$ \\
FBG $(\mathrm{mmol} / \mathrm{L})$ & $8.52(6.70,11.74)$ \\
TT3 $(\mathrm{nmol} / \mathrm{L})$ & $1.45(1.30,1.68)$ \\
TT4 $(\mathrm{nmol} / \mathrm{L})$ & $91.95(82.20,103.20)$ \\
TSH $(\mu / \mathrm{m} / \mathrm{mL})$ & $1.84(1.26,2.59)$ \\
HbAIc $(\%)$ & $8.90(7.60,10.80)$ \\
OC $(\mathrm{ng} / \mathrm{mL})$ & $11.59(9.15,14.20)$ \\
B-CTX $(\mathrm{ng} / \mathrm{mL})$ & $0.34(0.22,0.45)$ \\
PINP $(\mathrm{ng} / \mathrm{mL})$ & $35.66(27.65,45.64)$ \\
\hline
\end{tabular}

Abbreviations: BMI, Body mass index; TC, total cholesterol; TG, triglyceride; LDL-C, low-density lipoprotein cholesterol; HDL-C, high-density lipoprotein cholesterol; FBG, fasting blood glucose; TT3, total triiodothyronine; TT4, total thyroid hormone; TSH, thyroid-stimulating hormone; HbAlc, glycated hemoglobin; OC, osteocalcin; $\beta$-CTX, type I collagen carboxyterminal peptide beta special sequence; PINP, N-terminal propeptide of type I collagen.

between the two groups. The difference in BTMs between low TT3 group and control group is shown in Figure 1.

The serum HbA1c levels significantly increased in patients with low TT3 levels compared with patients with normal thyroid hormone levels $(\mathrm{P}<0.001)$. The baseline anthropometric and biochemical characteristics of the low TT3 group and control group are shown in Table 2.
Comparison of the Prevalence of Low TT3 Between the High HbAlc Group and Low HbAlc Group

The prevalence of low TT3 was significantly higher in high HbAlc group than in low HbAlc group $\left(\chi^{2}=\right.$ $20.493, \mathrm{P}<0.001)$. The levels of TT3 were significantly lower in the high HbAlc group than in the low HbAlc group $(\mathrm{P}<0.001)$.

\section{Correlations Between BTMs and TT3 Levels in Low TT3 Group}

OC was found to positively correlate with TT3 $(r=0.219$, $P=0.009$ ). Also, a significant positive correlation was observed between PINP and TT3 $(\mathrm{r}=0.206, P=0.019)$. However, there were no correlation between $\beta$-CTX and TT3 $(\mathrm{r}=-0.168, P=0.057)$ (Figure 2) (Table 3).

\section{Multivariate Linear Correlation Analysis of BTMs and TT3 Levels in Patients with T2DM}

For participants with low TT3 levels, TT3 levels were positively correlated with $\mathrm{OC}$ in the crude model 1 ( $\beta=6.803, P<0.001$ ), model 2 (adjusted for age, BMI, and duration of diabetes) $(\beta=7.948, \quad \mathrm{P}<0.001)$, model 3 (adjusted for age, BMI, duration of diabetes, TC, TG, HDL and LDL) $(\beta=9.135, \mathrm{P}<0.001)$, model 4 (adjusted for age, BMI, duration of diabetes, TC, TG, HDL, LDL,
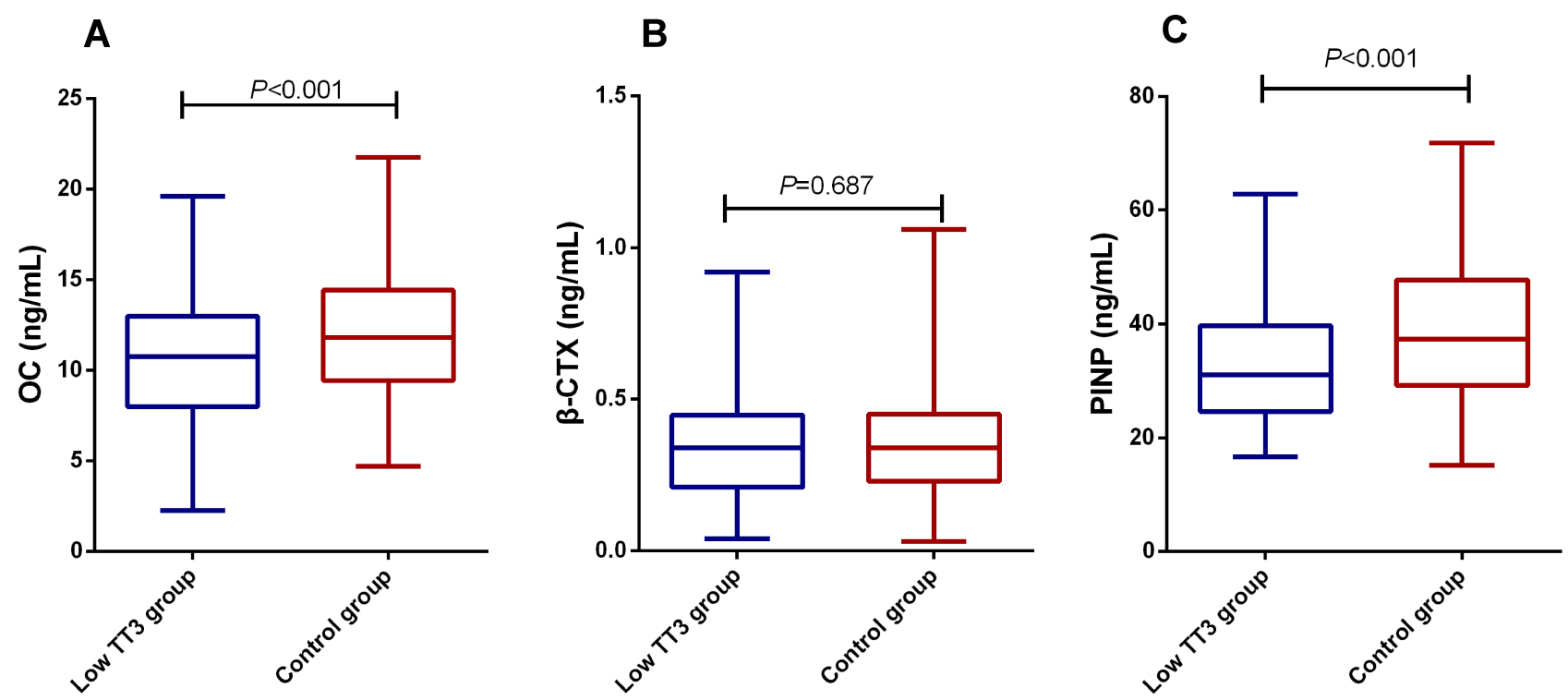

Figure I Comparisons of bone turnover markers levels in low TT3 group and control group in patients with type 2 diabetes mellitus. (A) Comparisons of OC levels in low TT3 group and control group in patients with type 2 diabetes mellitus. (B) Comparisons of $\beta$-CTX levels in low TT3 group and control group in patients with type 2 diabetes mellitus. (C) Comparisons of PINP levels in low TT3 group and control group in patients with type 2 diabetes mellitus. 
Table 2 Clinical Characteristics of All Patients with T2DM with and without Low TT3 Levels

\begin{tabular}{|c|c|c|c|}
\hline & $\begin{array}{l}\text { Low TT3 Group } \\
(n=141)\end{array}$ & $\begin{array}{l}\text { Control Group } \\
\qquad(n=436)\end{array}$ & $P$ \\
\hline Age (years) & $59.33 \pm 12.82$ & $58.00(49.00,66.75)$ & $<0.001$ \\
\hline $\begin{array}{l}\text { DM duration } \\
\text { (years) }\end{array}$ & $10.00(3.00,17.00)$ & $10.00(3.00,15.00)$ & 0.731 \\
\hline BMI $\left(\mathrm{kg} / \mathrm{m}^{2}\right)$ & $25.01 \pm 3.44$ & $26.03(23.72,28.33)$ & $0.001 *$ \\
\hline $\mathrm{TC}(\mathrm{mmol} / \mathrm{L})$ & $4.76(3.92,5.7 I)$ & $4.67(3.93,5.49)$ & 0.481 \\
\hline TG $(\mathrm{mmol} / \mathrm{L})$ & $1.31(0.93,1.92)$ & $1.45(1.04,2.13)$ & 0.062 \\
\hline LDL-C (mmol/L) & $2.98(2.17,3.75)$ & $2.92(2.15,3.53)$ & 0.383 \\
\hline HDL-C (mmol/L) & $1.14(0.96,1.42)$ & $1.09(0.92,1.35)$ & 0.450 \\
\hline FBG $(\mathrm{mmol} / \mathrm{L})$ & $8.73(6.42,12.66)$ & $8.44(6.71,11.01)$ & 0.311 \\
\hline TT3 (nmol/L) & $1.14(1.00,1.23)$ & $1.54(1.40,1.74)$ & $<0.00 I^{*}$ \\
\hline TT4 (nmol/L) & $86.90(76.19,94.61)$ & $94.24(84.93,104.68)$ & $<0.00 I^{*}$ \\
\hline $\mathrm{TSH}(\mu \mathrm{IU} / \mathrm{mL})$ & $1.72(1.08,2.5 \mathrm{I})$ & $1.87(1.30,2.62)$ & $0.034 *$ \\
\hline HbAlc (\%) & $9.86 \pm 2.26$ & $8.70(7.50,10.40)$ & $<0.00 I^{*}$ \\
\hline $\mathrm{OC}(\mathrm{ng} / \mathrm{mL})$ & $10.79 \pm 3.62$ & II.8I (9.43, I4.44) & $<0.00 I^{*}$ \\
\hline B-CTX (ng/mL) & $0.34(0.22,0.44)$ & $0.34(0.23,0.45)$ & 0.687 \\
\hline PINP (ng/mL) & $31.06(24.61,39.70)$ & $37.31(29.16,47.79)$ & $<0.00 I^{*}$ \\
\hline
\end{tabular}

Note: *Denotes significance at a $\mathrm{P}$ value of $<0.05$.

Abbreviations: BMI, Body mass index; TC, total cholesterol; TG, triglyceride; LDL-C, low-density lipoprotein cholesterol; HDL-C, high-density lipoprotein cholesterol; FBG, fasting blood glucose; TT3, total triiodothyronine; TT4, total thyroid hormone; TSH, thyroid-stimulating hormone; HbAlc, glycated hemoglobin; OC, osteocalcin; $\beta-C T X$, type I collagen carboxyterminal peptide beta special sequence; PINP, N-terminal propeptide of type I collagen.

FBG, HbA1c) $(\beta=8.255, \mathrm{P}<0.001)$, model 5 (adjusted for age, BMI, duration of diabetes, TC, TG, HDL, LDL, FBG, HbA1c, TT4, TSH) $(\beta=6.632, \mathrm{P}=0.005)$ (Table 4).

Also, TT3 levels were positively correlated with PINP levels in patients with low TT3 levels, regardless of whether an unadjusted or adjusted model was used (model 1: $\beta=17.683, \quad \mathrm{P}=0.001$; model 2: $\beta=20.848$, $\mathrm{P}=0.001 ;$ model 3 : $\beta=24.104, \quad \mathrm{P}<0.001 ;$ model 4 : $\beta=21.211, \quad P=0.002 ; \quad$ model $5: \quad \beta=19.784, \quad P=0.008$ ) (Table 5).

However, TT3 levels were not associated with $\beta$-CTX levels in patients with low TT3 levels, regardless of whether an unadjusted or adjusted model was used (model 1: $\beta=-0.181, \mathrm{P}=0.065$; model 2: $\beta=-0.128$, $\mathrm{P}=0.259$; model 3 : $\beta=-0.109, \mathrm{P}=0.3651$; model $4: \beta=$ $-0.170, \mathrm{P}=0.183$; model 5: $\beta=-0.207, \mathrm{P}=0.123$ ) (Table 6).

\section{Comparisons of BTMs in the Low TT3 Group After Dividing Patients into Four Groups Based on Their Serum TT3 Levels}

Patients with T2DM and low TT3 levels were divided into four groups according to their TT3 levels: group 1, TT3 < $1.00 \mathrm{nmol} / \mathrm{L}$; group $2,1.00 \mathrm{nmol} / \mathrm{L} \leq \mathrm{TT} 3<1.10 \mathrm{nmol} / \mathrm{L}$; group 3, $1.10 \mathrm{nmol} / \mathrm{L} \leq \mathrm{TT} 3<1.20 \mathrm{nmol} / \mathrm{L}$; and group 4 , $1.20 \mathrm{nmol} / \mathrm{L} \leq \mathrm{TT} 3<1.30 \mathrm{nmol} / \mathrm{L}$.

The difference in BTMs among the four groups is shown in Figure 3. On categorizing patients into four groups according to TT3 levels, differences were noted in OC and PINP levels between at least two of the four groups $(\mathrm{P}=0.008$ and $\mathrm{P}=0.022$, respectively). After a pairwise comparison, the OC and PINP levels were significantly lower in patients with TT3 $<1.00 \mathrm{mmol} / \mathrm{L}$ than in those with TT3 $\geq 1.00 \mathrm{mmol} / \mathrm{L}$. No difference was found in $\beta$-CTX $(P=0.276)$ among the four groups (Table 7).

\section{Discussion}

To our knowledge this is first study examining the relationship between low TT3 levels and BTMs in T2DM patients without thyroid disease. Seppel et al found no significant difference in OC levels between patients with low T3 levels and healthy people; no correlation was found between $\mathrm{OC}$ and $\mathrm{T} 3,{ }^{7}$ but all of this subjects without T2DM. This study was novel in reporting that T2DM patients with low TT3 levels had lower OC and PINP
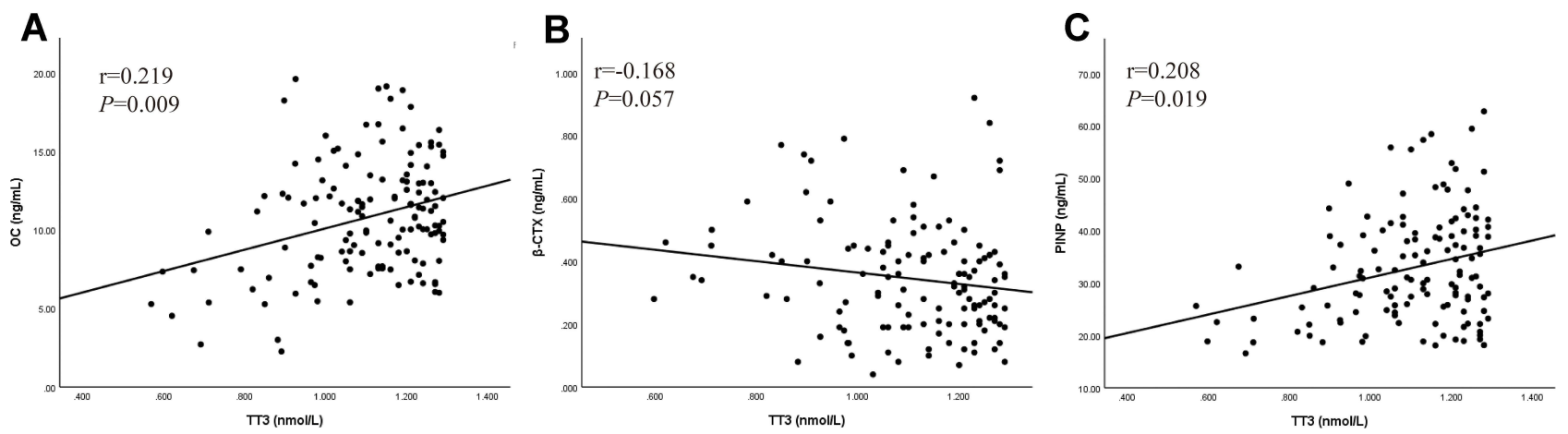

Figure 2 The correlation between bone turnover markers levels and TT3 levels in the low TT3 group. (A) The correlation between OC levels and TT3 levels in the low TT3 group. (B) The correlation between $\beta$-CTX levels and TT3 levels in the low TT3 group. (C) The correlation between PINP levels and TT3 levels in the low TT3 group. 
Table 3 Correlation Between BTMs and Other Parameters in T2DM Patients with Low TT3 Levels

\begin{tabular}{|l|l|l|l|l|}
\hline & & OC & B-CTX & PINP \\
\hline BMI $\left(\mathrm{kg} / \mathrm{m}^{2}\right)$ & $r$ value & -0.085 & -0.169 & 0.070 \\
& $P$-value & 0.334 & 0.063 & 0.446 \\
\hline TC $(\mathrm{mmol} / \mathrm{L})$ & $r$ value & 0.129 & 0.041 & 0.168 \\
& $P$-value & 0.139 & 0.653 & 0.063 \\
\hline TG $(\mathrm{mmol} / \mathrm{L})$ & $r$ value & -0.012 & 0.111 & 0.049 \\
& $P$-value & 0.888 & 0.219 & 0.588 \\
\hline LDL-C $(\mathrm{mmol} / \mathrm{L})$ & $r$ value & 0.064 & -0.011 & 0.132 \\
& $P$-value & 0.457 & 0.902 & 0.140 \\
\hline HDL-C $(\mathrm{mmol} / \mathrm{L})$ & $r$ value & 0.235 & 0.016 & 0.101 \\
& $P$-value & $0.006^{*}$ & 0.194 & 0.263 \\
\hline FBG $(\mathrm{mmol} / \mathrm{L})$ & $r$ value & -0.238 & -0.066 & -0.143 \\
& $P$-value & $0.005^{*}$ & 0.455 & 0.106 \\
\hline HbAlc $(\%)$ & $r$ value & -0.202 & 0.035 & -0.150 \\
& $P$-value & 0.020 & 0.694 & 0.095 \\
\hline TT3 $(\mathrm{nmol} / \mathrm{L})$ & $r$ value & 0.219 & -0.168 & 0.206 \\
& $P$-value & $0.009 *$ & 0.057 & $0.019 *$ \\
\hline TT4 $(\mathrm{nmol} / \mathrm{L})$ & $r$ value & 0.188 & 0.159 & 0.114 \\
& $P$-value & $0.027^{*}$ & 0.071 & 0.198 \\
\hline TSH $(\mu \mathrm{lU} / \mathrm{mL})$ & $r$ value & 0.135 & -0.222 & 0.140 \\
& $P$-value & 0.113 & $0.011 *$ & 0.114 \\
\hline
\end{tabular}

Note: *Denotes significance at a $P$ value of $<0.05$.

Abbreviations: BMI, Body mass index; TC, total cholesterol; TG, triglyceride; LDL-C, low-density lipoprotein cholesterol; HDL-C, high-density lipoprotein cholesterol; FBG, fasting blood glucose; TT3, total triiodothyronine; TT4, total thyroid hormone; TSH, thyroid-stimulating hormone; HbAlc, glycated hemoglobin; OC, osteocalcin; $\beta$-CTX, type I collagen carboxyterminal peptide beta special sequence; PINP, N-terminal propeptide of type I collagen.

Table 4 Correlation Between TT3 and OC in Patients with Low TT3 Levels

\begin{tabular}{|c|c|c|c|c|c|}
\hline & B (95\% CI) & Std.Error & Beta & t & $P$ \\
\hline Model I & $6.803(3.252,10.353)$ & 1.795 & 0.308 & 3.789 & $<0.001$ \\
Model 2 & $7.948(4.131,11.764)$ & 1.929 & 0.346 & 4.121 & $<0.001$ \\
Model 3 & $9.135(5.223,13.047)$ & 1.975 & 0.401 & 4.625 & $<0.001$ \\
Model 4 & $8.225(4.051,12.459)$ & 2.122 & 0.360 & 3.891 & $<0.001$ \\
Model 5 & $6.632(2.065,11.199)$ & 2.304 & 0.289 & 2.878 & 0.005 \\
\hline
\end{tabular}

Table 5 Correlation Between TT3 and PINP in Patients with Low TT3 Levels

\begin{tabular}{|c|c|c|c|c|c|}
\hline & B (95\% Cl) & Std.Error & Beta & t & $\boldsymbol{P}$ \\
\hline Model I & $17.683(6.948,28.418)$ & 5.425 & 0.278 & 3.260 & 0.001 \\
Model 2 & $20.848(8.842,32.855)$ & 6.063 & 0.309 & 3.439 & 0.001 \\
Model 3 & $24.104(11.679,36.530)$ & 6.268 & 0.361 & 3.846 & $<0.001$ \\
Model 4 & $21.211(7.856,34.566)$ & 6.733 & 0.314 & 3.150 & 0.002 \\
Model 5 & $19.784(5.249,34.318)$ & 7.326 & 0.293 & 2.700 & 0.008 \\
\hline
\end{tabular}

Table 6 Correlation Between TT3 and $\beta$-CTX in Patients with Low TT3 Levels

\begin{tabular}{|c|c|c|c|c|c|}
\hline & B (95\% CI) & $\begin{array}{c}\text { Std. } \\
\text { Error }\end{array}$ & Beta & t & $P$ \\
\hline Model I & $-0.181(-0.374,0.011)$ & 0.097 & -0.164 & -1.863 & 0.065 \\
Model 2 & $-0.128(-0.352,0.095)$ & 0.113 & -0.108 & -1.136 & 0.259 \\
Model 3 & $-0.109(-0.346,0.128)$ & 0.120 & -0.093 & -0.909 & 0.365 \\
Model 4 & $-0.170(-0.421,0.081)$ & 0.126 & -0.144 & -1.341 & 0.183 \\
Model 5 & $-0.207(-0.470,0.057)$ & 0.133 & -0.176 & -1.557 & 0.123 \\
\hline
\end{tabular}

levels compared with those with normal thyroid hormone levels. Furthermore, in the low TT3 group, TT3 positively correlated with OC and PINP, regardless of whether confounding factors were adjusted for.

Thyroid hormones are necessary for bone growth, maturation, basic metabolism, and bone turnover. Bone turnover is a periodic dynamic process involving bone formation and bone resorption. ${ }^{8}$ The imbalance between bone formation and bone resorption can lead to osteoporosis. OC and PINP are bone formation markers. OC is the most sensitive marker reflecting osteogenic cell activity and bone formation, and PINP is the specific sensitive indicator reflecting new bone formation. The results of this study suggested that low TT3 levels are associated with impaired bone formation, may can lead to a low bone turnover state and may cause osteoporosis. So, we hypothesize that low TT3 levels may are a risk factor of osteoporosis for patients with T2DM, although they have normal TT4 and TSH levels. Further, finding that bone formation was significantly impaired in this study when the TT3 level was $<1.00 \mathrm{mmol} / \mathrm{L}$ was of great clinical significance. This suggested that an intervention is required to prevent osteoporosis when TT3 was $<1.00$ $\mathrm{mmol} / \mathrm{L}$ in patients with T2DM.

Accordingly, underlying mechanisms of impaired bone formation due to low TT3 remain unexplored. The underlying mechanism may be that T3 can act directly or indirectly influence osteoblasts. The T3 receptor also exists in bone tissue; T3 can effect osteoblasts by binding to the T3 receptor in the nucleus. ${ }^{9,10} \mathrm{~T} 3$ mainly acts on osteoblasts, regulates intramembranous and endochondral ossification, and controls the efficiency of bone formation, bone maturation, and mineralization. ${ }^{11}$ Thyroid hormones could not only directly bind to thyroid receptors in bone tissue but also induce the production of growth factors and metalloproteinases, stimulating osteoblast differentiation and increase osteoblast activity, thus affecting the balance of bone turnover. ${ }^{12}$ 

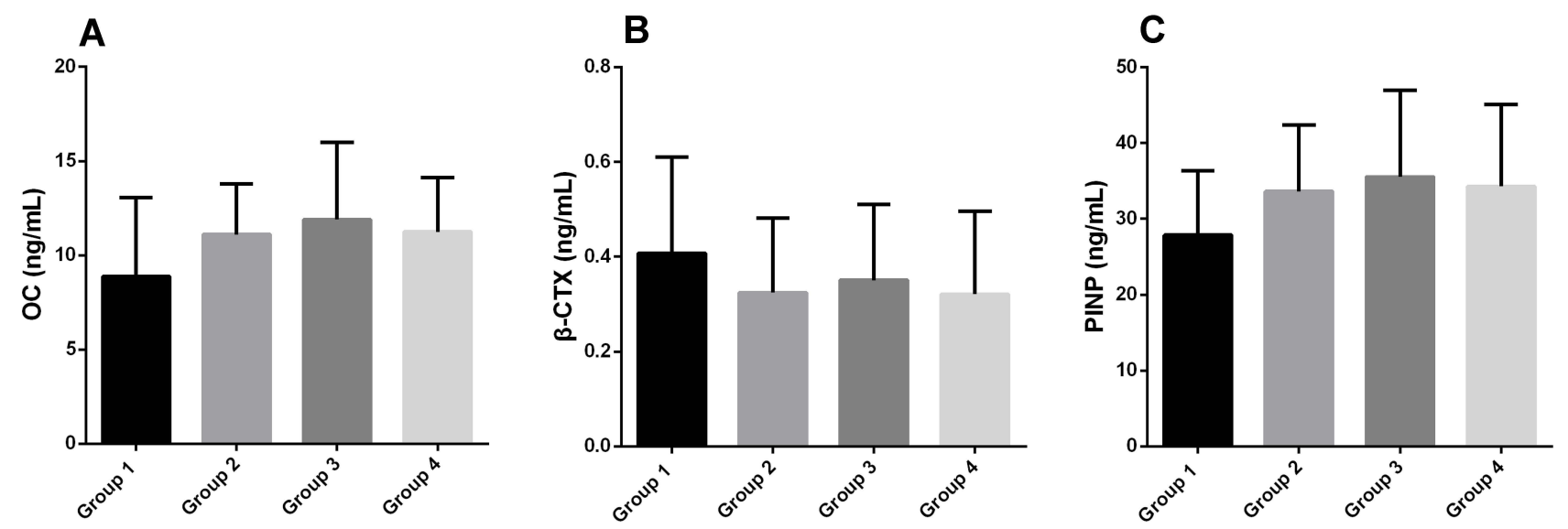

Figure 3 BTMs of patients with T2DM and low TT3 levels, stratified according to serum TT3 levels. (A) Comparisons of OC levels in four groups. (B) Comparisons of $\beta$ CTX levels in four groups. (C) Comparisons of PINP levels in four groups.Group I: TT3 < I.00 nmol/L; Group 2:1.00 nmol/L $\leq$ TT3 < I. I0 nmol/L; Group 3:I.10 nmol/L $\leq$ $\mathrm{TT} 3<1.20 \mathrm{nmol} / \mathrm{L}$; and Group $4: 1.20 \mathrm{nmol} / \mathrm{L} \leq \mathrm{TT} 3<1.30 \mathrm{nmol} / \mathrm{L}$.

The relationship betweenT2DM and thyroid hormones is a complex one. Such patients are more susceptible to have low TT3 levels, especially when the HbA1c level is higher than $10.5-11 \% .^{13,14}$ This study also found that the low TT3 group had significantly higher HbA1c levels compared with control group. The prevalence of low TT3 levels was significantly higher in patients with $\mathrm{HbA} 1 \mathrm{c} \geq 10.5 \%$ than in patients with $\mathrm{HbA} 1 \mathrm{c}<10.5 \%$ (P $<0.001)$. These findings indicated that patients with T2DM and low TT3 levels had more inadequate blood glucose control. Long-term hyperglycemia can directly damage osteoblasts ${ }^{15}$ and also produce excessive reactive oxygen species to induce the apoptosis of osteoblasts, ${ }^{16}$ ultimately reducing bone formation and leading to a low bone turnover state. Patients with T2DM and low TT3 levels had a higher HbAlc level, and hyperglycemia could impair bone formation, which might also be a cause of the low bone turnover state in the low TT3 group.

There were limitations to this study. First, our study is that this is based on data from a single center, so the conclusion found in our study could not be extrapolated to all T2DM patients, thus necessitating the need for further large-scale studies on different centers and hospitals. Second, the free T3 and free T4 levels should be considered in future studies of thyroid function.

In conclusion, this study may have important clinical implications. The results of our study would suggest that TT3 values lower than $1 \mathrm{mmol} / \mathrm{L}$, even TT4 and TSH in the reference range, may be not safe for bone metabolism in T2DM patients. Finally, our data would encourage to measure thyroid hormones in all T2DM patients even in the absence of thyroid disease.

\section{Conclusions}

In conclusion, this study found that OC and PNIP levels significantly decreased in patients with T2DM and low TT3 levels, and TT3 positively correlated with OC and PINP. It hypothesize that low TT3 levels may are a risk factor of osteoporosis for patients with T2DM. And we suggested that even if patients with T2DM did not suffer from hypothyroidism, early intervention should be taken to prevent the occurrence and development of osteoporosis when the TT3 $<1.00 \mathrm{mmol} / \mathrm{L}$.

Table 7 Comparison of BTMs in the Low TT3 Group, Stratified According to the Serum TT3 Level

\begin{tabular}{|c|c|c|c|c|c|}
\hline & $\begin{array}{c}\text { TT3 }<\text { I.00 nmol } / \\
\text { L N }=35\end{array}$ & $\begin{array}{c}1.00 \mathrm{nmol} / \mathrm{L} \leq \mathrm{TT} 3<\mathrm{I.10} \\
\mathrm{nmol} / \mathrm{L} \mathrm{N}=24\end{array}$ & $\begin{array}{c}1.10 \mathrm{nmol} / \mathrm{L} \leq \mathrm{TT} 3<\mathrm{I} .20 \\
\mathrm{nmol} / \mathrm{L} \mathrm{N}=29\end{array}$ & $\begin{array}{c}1.20 \mathrm{nmol} / \mathrm{L} \leq \mathrm{TT} 3<\mathrm{I} .30 \\
\mathrm{nmol} / \mathrm{L} \mathrm{N}=53\end{array}$ & $\mathbf{P}$ \\
\hline $\mathrm{OC}(\mathrm{ng} / \mathrm{mL})$ & $8.87 \pm 4.19$ & $11.10 \pm 2.70$ & II.38 (8.74-I2.5I) & $11.24 \pm 2.89$ & $0.008^{*}$ \\
\hline B-CTX (ng/mL) & $0.41 \pm 0.20$ & $0.32 \pm 0.16$ & $0.35 \pm 0.16$ & $0.29(0.21-0.39)$ & 0.276 \\
\hline PINP (ng/mL) & $15.62(20.70-32.99)$ & $33.60 \pm 8.80$ & $35.42 \pm 11.66$ & $34.27 \pm 10.84$ & $0.022 *$ \\
\hline
\end{tabular}

Note: *Denotes significance at a $P$ value of $<0.05$.

Abbreviations: TT3, Total triiodothyronine; OC, osteocalcin; $\beta$-CTX, type I collagen carboxyterminal peptide beta special sequence; PINP, N-terminal propeptide of type I collagen. 


\section{Disclosure}

The authors report no conflicts of interest in this work.

\section{References}

1. Ozair M, Noor S, Raghav A, Siddiqi SS, Chugtai AM, Ahmad J. Prevalence of thyroid disorders in North Indian Type 2 diabetic subjects: a cross sectional study. Diabetes Metab Syndr. 2018;12 (3):301-304. doi:10.1016/j.dsx.2017.12.016

2. Zhu Y, Xu F, Shen J, et al. Prevalence of thyroid dysfunction in older Chinese patients with type 2 diabetes-A multicenter cross-sectional observational study across China. PloS one. 2019;14(5):e0216151.

3. Zeng Q, Li N. The prevalence of osteoporosis in China, a Nationwide, Multicenter DXA Survey. J Bone Miner Res. 2019;34(10):1789-1797. doi:10.1002/jbmr.3757

4. Völzke H, Krohn U, Wallaschofski H, Lüdemann J, John U, Kerner W. The spectrum of thyroid disorders in adult type 1 diabetes mellitus. Diabetes Metab Res Rev. 2007;23(3):227-233. doi:10.1002/dmrr.676

5. Lademann F, Tsourdi E, Hofbauer LC, Rauner M. Thyroid hormone actions and bone remodeling - The role of the Wnt signaling pathway. Exp Clin Endocrinol Diabetes. 2020;128(6-07):450-454. doi:10.1055/ a-1088-1215

6. Wojcicka A, Bassett JH, Williams GR. Mechanisms of action of thyroid hormones in the skeleton. Biochim Biophys Acta. 2013;1830 (7):3979-3986. doi:10.1016/j.bbagen.2012.05.005

7. Seppel T, Becker A, Lippert F, Schlaghecke R. Serum sex hormone-binding globulin and osteocalcin in systemic nonthyroidal illness associated with low thyroid hormone concentrations. J Clin Endocrinol Metab. 1996;81 (4):1663-1665. doi:10.1210/jcem.81.4.86136386

8. Kremer R, Gilsanz V. Fat and bone: an odd couple. Front Endocrinol (Lausanne). 2015;6:190. doi:10.3389/fendo.2015.00190
9. Bianco AC, Salvatore D, Gereben B, Berry MJ, Larsen PR Biochemistry, cellular and molecular biology, and physiological roles of the iodothyronine selenodeiodinases. Endocr Rev. 2002;23 (1):38-89.

10. Williams AJ, Robson H, Kester MHA, et al. Iodothyronine deiodinase enzyme activities in bone. Bone. 2008;43(1):126-134. doi:10.1016/j.bone.2008.03.019

11. Duncan bassett JH, Williams GR. Analysis of physiological responses to thyroid hormones and their receptors in bone. Methods Mol Biol. 2018;1801:123-154.

12. Barnard JC, Williams AJ, Rabier B, et al. Thyroid hormones regulate fibroblast growth factor receptor signaling during chondrogenesis. Endocrinology. 2005;146(12):5568-5580. doi:10.1210/en.2005-0762

13. Moura Neto A, Parisi MC, Tambascia MA, Alegre SM, Pavin EJ, Zantut-Wittmann DE. The influence of body mass index and low-grade systemic inflammation on thyroid hormone abnormalities in patients with type 2 diabetes. Endocr J. 2013;60(7):877-884. doi:10.1507/endocrj.EJ13-0030

14. Yuan Z, Xu X, Ye H, Jin L, Zhang X, Zhu Y. High levels of plasma selenium are associated with metabolic syndrome and elevated fasting plasma glucose in a Chinese population: a case-control study. $J$ Trace Elem Med Biol. 2015;32:189-194. doi:10.1016/j. jtemb.2015.07.009

15. Dobnig H, Piswanger-Solkner JC, Roth M, et al. Type 2 diabetes mellitus in nursing home patients: effects on bone turnover, bone mass, and fracture risk. J Clin Endocrinol Metab. 2006;91 (9):3355-3363. doi:10.1210/jc.2006-0460

16. Hussein RM. Biochemical relationships between bone turnover markers and blood glucose in patients with type 2 diabetes mellitus. Diabetes Metab Syndr. 2017;11(Suppl 1):S369-s72. doi:10.1016/j. dsx.2017.03.018

\section{Publish your work in this journal}

Diabetes, Metabolic Syndrome and Obesity: Targets and Therapy is an international, peer-reviewed open-access journal committed to the rapid publication of the latest laboratory and clinical findings in the fields of diabetes, metabolic syndrome and obesity research. Original research, review, case reports, hypothesis formation, expert opinion and commentaries are all considered for publication. The manuscript management system is completely online and includes a very quick and fair peer-review system, which is all easy to use. Visit http://www.dovepress.com/testimonials.php to read real quotes from published authors. 